\title{
Article
}

\section{We're All Cultural Historians Now: Revolutions In Understanding Archaeological Theory And Scientific Dating}

\author{
Griffiths, Seren
}

Available at http://clok.uclan.ac.uk/20622/

Griffiths, Seren ORCID: 0000-0001-5168-9897 (2017) We're All Cultural Historians Now: Revolutions In Understanding Archaeological Theory And Scientific Dating. Radiocarbon, 59 (S5). pp. 1347-1357. ISSN 0033-8222

It is advisable to refer to the publisher's version if you intend to cite from the work. http://dx.doi.org/10.1017/RDC.2017.20

For more information about UCLan's research in this area go to http://www.uclan.ac.uk/researchgroups/ and search for <name of research Group>.

For information about Research generally at UCLan please go to http://www.uclan.ac.uk/research/

All outputs in CLoK are protected by Intellectual Property Rights law, including Copyright law. Copyright, IPR and Moral Rights for the works on this site are retained by the individual authors and/or other copyright owners. Terms and conditions for use of this material are defined in the policies page.

\section{CLoK}

Central Lancashire online Knowledge www.clok.uclan.ac.uk

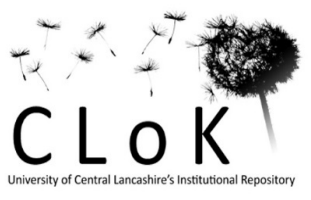




\title{
WE'RE ALL CULTURAL HISTORIANS NOW. REVOLUTIONS IN UNDERSTANDING IN ARCHAEOLOGICAL THEORY AND SCIENTIFIC DATING
}

Seren Griffiths

University of Central Lancashire, Preston, PR1 2HE. United Kingdom Email: SGriffiths7@uclan.ac.uk

\begin{abstract}
Radiocarbon dating has had profound implications for archaeological understanding. These have been identified as various "revolutions", with the latest - Bayesian chronological statistical analyses of large datasets - hailed as a "revolution in understanding". This paper argues that the full implications of radiocarbon data and interpretation on archaeological theory have yet to be recognized, and it suggests that responses in Britain to earlier revolutions in archaeological understanding offer salutary lessons for contemporary archaeological practice. This paper draws on the work of David Clarke and Colin Renfrew to emphasize the importance of critical considerations of the relationships between archaeological theory and scientific method, and to emphasize that seemingly neutral aspects of archaeological thought are highly laden interpretatively, having significant implications for the kinds of archaeology that we write.
\end{abstract}

\section{INTRODUCTION}

The starting point for this paper was a reflection on the "radiocarbon revolutions" and the implications they have had on archaeological narratives generally, and studies of Neolithic material culture in Britain specifically. There have been at least four radiocarbon "revolutions": the introduction of the method, the recognition of the need for calibration, the reduction in sample size facilitated by accelerator mass spectrometry, and Bayesian statistical analysis of radiocarbon measurements (Bronk Ramsey 2008; Bayliss 2009). The recent application of Bayesian modeling to Neolithic prehistory in Britain and Ireland has led to a significant leap forward in understandings (e.g. Whittle et al. 2011; Whitehouse et al. 2014), however beyond the development of more precise chronologies I argue that the introduction of Bayesian modeling has wide ranging importance for the kinds of 
archaeology that we write. Two reactions to the introduction of radiocarbon dating — those of David Clarke and Colin Renfrew — are particularly relevant for current archaeological practice in the light of the "Bayesian revolution".

I suggest that the logical repercussions of the Bayesian revolution have not yet been fully worked through by many in the archaeological community, and the use of Bayesian analyses has wider significance for the kinds of archaeologies we write. Specifically, I argue that aspects of prehistory in Britain maintains a culture historic approach, decades after the rejection of Childe's model (cf. Thomas 1996, 97), with archaeological evidence reified into chronologically and culture historically pre-defined entities divorced from the material basis. The result is that the narratives that we generate adopt what Thomas (1996) describes as a totalizing or idealized nature, which are not as sophisticated as they might be.

\section{DESCRIPTIVE BACKGROUND}

\section{Dating the Neolithic of Ireland and Britain}

Recent research into Neolithic Britain and Ireland (Whittle et al. 2011; Whitehouse et al. 2014) has provided precise, robust and probabilistic chronologies for an area prehistory that previously was described in only the most imprecise chronological schemes. At the general national scale, it has provided an appreciation of the tempo of changes in material culture and site types that was wholly absent before the application of Bayesian analyses. At the regional scale, fine-grained chronology allows us new understandings of the context of change. This has included for example the demonstration for the first time of overlap between people using hunter-gatherer-fisher Mesolithic material culture and people engaging with Neolithic farming strategies in the same landscapes (Griffiths 2014a; 2014b), and has identified regions where processes of neolithization were more complex than are previously recognized (Griffiths 2016).

The implications of the application of Bayesian modeling in Neolithic studies can be directly compared to the responses to the development of 
the radiocarbon technique in the mid $20^{\text {th }}$ century, which noted Neolithic scholar Glyn Daniel (Daniel 1986) declared the greatest breakthrough in the history of archaeology. The initial application of radiocarbon rendered null-and-void diffusionist theses about the development of north-west Europe Neolithic tombs from Mediterranean examples (cf. Daniel 1941; Daniel 1970), and was revelatory in demonstrating the antiquity of sites. The impact was so profound that some intial measurements were regarded with suspicion; the eminent prehistorian Stuart Piggott famously declared the emerging prehistoric chronology for the Stonehenge landscape as “...archaeologically unacceptable..." (Piggott 1959, 289).

The revised "long chronology" for the British Neolithic that radiocarbon produced challenged both the causal processes (the diffusion model of British Neolithic monuments from the Mediterranean) and the narrative structure (the duration of prehistory) which provided the organizational structure for previous archaeological thought. Archaeological data - observations about stratigraphic relationships, schemes of material culture, isotopic measurements on organic materials and so on - are always heavily enmeshed in the context in which knowledge is produced; the reordering of prehistory using radiocarbon data provided independent means of assessing the magnitude of our situated approach to our knowledge production.

\section{Scientific dating and theory}

The context of the first and second radiocarbon revolutions was one of change in archaeological theory in the mid $20^{\text {th }}$ century, occurring at the disjunction between "Culture History" archaeological approaches and "New" or "Processual" archaeological approaches (Trigger 2006; Johnson 1999). Calibrated radiocarbon dates were at the vanguard of archaeological approaches which emphasized the discipline as science. In Britain, the reactions of two Cambridge scholars - Colin Renfrew and David Clarke, both proponents of "Processual" or "New" approaches (Daniel 1981, 192) - to radiocarbon have important implications for the discipline in the light of the "Bayesian revolution".

Beyond the classification of Renfrew and Clarke as "New" 
archaeologists, I believe it is possible to identify wider themes in their reactions and approaches with reference to Enlightenment and Romantic histories of intellectual thought (Sherratt 1996, 141). These two personalities responded in markedly different ways, with subtle distinctions in empahsis. Both these scholars were interested in the role of "Science" in archaeology, but also - in different ways - in "Revolutions" in intellectual thought and archaeological understandings.

Colin Renfrew produced his Neolithic Investigations in Orkney in 1979. Renfrew's work emphasized the importance of writing generally about the process of constructing Neolithic monuments, and his interest in providing sequence and order using radiocarbon data privileged the standard application of the technique. Onto these data Renfrew hung a model of social change from a territory based, segmentary society to a centralized chiefdom society with associated changes in material culture. Renfrew worked from chronological sequence, to causality, narrative, and interpretation, emphasizing the importance of data. In another key work Renfrew outlined the belief at the time that "...all that was needed was a couple of ounces of charcoal...and science would do the rest..." (Renfrew 1976, 53; my emphasis). Renfrew's chronologies were by no means as precise as those now available for certain periods through Bayesian modeling, but the impact of sequence especially on understanding was comparable to the recent changes in British and Irish Neolithic studies.

A couple of years before Renfrew's review of the role of radiocarbon in archaeology, a very different emphasis was outlined by David Clarke. Clarke published his paper on the loss of intellectual innocence, noting that the "...chronological consequences of isotope and other dating methods...have infiltrated archaeological thinking in a manner which has largely concealed the significance of their repercussions" (Clarke 1973, 10; my emphasis). What Clarke recognized amongst other things, was the challenges these new chronologies presented to archaeological practice, not simply in terms of accounting for a better ordered sequence of events, but in how to situate these new data within received models of the past, and moreover whether received models were appropriate settings. Clarke noted the inherently situated nature of 
archaeological temporal models, and the importance of chronology as loaded and subjective interpretations even if they may appear to be neutral and unbiased. In Clarke's (1973, 10; my emphasis) words:
"Under the ultra-short chronologies, archaeological time was confused with historical time and seemed packed with data and events; large-scale phenomena appeared to take place in swift interludes - hence the prevalence of 'invasion' explanations...A fundamental lesson emerges - the consequences arising from the introduction of new methodologies are of far greater significance than the new introductions themselves...The first thing we may deduce from this revision is that many of our taxonomic entity divisions are defined by lines drawn through gaps in the evidence and zones of greatest ignorance; this does not make these taxa invalid but it does gravely alter what constitutes meaningful manipulation and explanation of such entities."

Clarke's key observation is that archaeological chronologies are not composed of neutral "facts". The seemingly benign sequences which we seek to populate with data are charged with interpretative value. This can be seen at its most obvious in a brief comparison of analytical concepts in prehistory. For example, the term "Neolithic was first coined by John Lubbock $(1865,3)$ who distinguished between Neolithic polished stone tools and Paleolithic implements. V. G. Childe (1940) identified the Neolithic by the radical (revolutionary) break in economic or subsistence modes from hunter-gatherer ways of life. Piggott (1954) populated the Neolithic with a series of "cultures" indicative of different origins, and which changed over time. Key to all these theses was the basis of classification, in Clarke's terms the taxonomy of the material under study. The definition of this term changes but the concept as analytical unit is enough to continue as chronological entity.

Childe's mastery of the discipline was in part because he was able to synthesize a wide range of evidence from across Europe into clearly defined tables or models of cultures (fig. 1). This clarity comes from 
drawing lines through evidence, of defining and domesticating it, and of doing away with ambiguity. As Andrew Sherratt (1996) noted, in 1938 Childe actually had two schemes for European Neolithic material culture, the one suggesting that European evidence predated Near Eastern examples was rejected because "...European cultures were always retarded in relation to Near Eastern ones...Thus his chronology was already implicit in his choice of model" (Sherratt 1996, 181; my emphasis). But of course Childe's systemization of European prehistory also codified it (Sherratt 1979, 198).

In his 1972, Clarke discussed the roles of models in archaeological thinking. At the broadest level, he differentiated between "operational" and "controlling" models. Operational models are those conceptual tools we employ in interpretations of archaeological data. The largely subconscious controlling models are those that are accumulated over time and which reflect personal approaches and predispositions, but which owe much to the prevailing intellectual approaches of the time. Clarke (1972, 5; cf. Lucas 2016) defined controlling models with reference to Kuhnian paradigms, "encapsulating" archaeologists within our operational practices. Within Clarke's operational class is a whole subset of models (fig. 2) that should allow archaeological practice to test hypotheses. Some of these operational models can have profound implications, challenging the legitimacy of controlling models (in Clarke's terms), or paradigms (cf. Lucas 2016); this can been seen for example in the use of ethnographic analogies and challenges to the fundamental approaches to interpretation which occurred as part of the Binford-Bordes Mousterian debate (Binford 1972). As Clarke notes $(1972,40)$, this has epistemological implications for the remit of archaeological interpretation — "...the overwhelming justification for the need to explore rather than ignore the use of models in archaeology" (Clarke 1972, 40; my emphasis).

Within Clarke's operational models, it is possible to identify model types from those that Orton (2004) defined as simplifications of physical entities (such as Harris matrices) to those providing much broader representations of social organization. Operational models may have different characteristics - the degree of abstraction or inclusion of "real life" evidence, but they are unified in that they should be used 
as devices to interrogate evidence (fig. 2). Within these models are Clarke's "iconic analogues", a class which includes plans, maps and graphs. These might seem to be simple abstractions of physical entities. However, because of their effectiveness and pervasiveness as abstractions, such models can become "of the thing themselves". As iconic analogues, these devices can take on a tangible reality; in the most dangerous cases archaeological interpretative constructs can become mistaken for the objects of inquiry.

In Renfrew's response, which focuses on the ordering aspects of radiocarbon data and emphasis on the collection of data, I believe we can see more "Enlightenment" tendencies (in Sherratt's model). In Clarke's response, I believe we see an emphasis on the relative, contextual nature of the production of knowledge that in Sherratt's terms cast Clarke as a Romantic (fig. 3).

I suggest that many chronological models can be classed as Clarke's iconic analogues (fig. 2). They are representations of time and space, with time and space scales on which to sit our data. Sometimes in chronological models archaeologists mistake the scales for what is being measured; a radiocarbon "date" has no inherent temporal quality, it is a measurement. As Clarke $(1972,13)$ noted, time and space "...exist because of the observed phenomena and not vice versa...". Everything else - all the variability in the distribution of material in time and space - is just "culture", or a filtering of the distribution of material by cultural processes. Material culture only works as a unit of study - as things to research and find out more about - if "culture" is not defined dependent on its position in time or space. If culture is defined as "period" then there is a logical fallacy. If we seek to explore change, like the transition from one way of life to another, but we predetermine that one form of activity occurs during one time period and another form of activity occurs in a later time period, then we will automatically predetermine the output of our investigation. This tension between the analytical categories we employ and the units of measurement is a conceptual one, not a clash of chronological systems (pace Lucas 2005, 9; cf. Griffiths in prep.).

In many cases our "neutral" models of the past structure a 
unidirectional, linear, teleological approach to writing archaeological narratives. Ultimately these neutral and routine ways of modeling "culture" derive from understandings of typology as part of the Three Age system (e.g. Montelius 1899; cf. Gräslund1987), reified and domesticated by the Culture Historians of the $19^{\text {th }}$ and $20^{\text {th }}$ centuries. While the interpretive aspects of the section drawing, context descriptions, and stratigraphic matrices have been recognized as part of the practice of doing archaeology (e.g. Patrick 1985), the important, latent, and structuring aspects of how we model activity over time has been under recognized. The pervasiveness of these models means that the period construct of culture ("the Neolithic") has become an intellectually constructed "truth" which exists across schools or thought or paradigms.

Lucas $(2016,7)$ has suggested that in archaeology, classifications or typologies are paradigmatic, with the "Neolithic" as a symbolic generalization or paradigm. I would suggest that the idea that we have an ability to systematize material culture into historically successive entities represents the more significant controlling model or paradigm. At its most extreme, chronologically-defined cultural successive models are incommensurate with narratives of transition, or overlap between these entities; models of period-defined cultural change which should be explicitly acknowledged as theoretical constructs - in fact assume an orthodoxy so powerful as to exist as facts that overarch changes even between supposedly radically different archaeological schools of thought.

\section{WRITING ABOUT TIME: A BRITISH NEOLITHIC CASE STUDY}

It was not very long ago that discussions of the Irish and British late Mesolithic and early Neolithic described the timing of the transition in relatively abstract terms - using phrases like "a couple of hundred years", "the early $4^{\text {th }}$ millennium", "the first centuries of the $4^{\text {th }}$ millennium" and so on. Now, thanks to the work of Alasdair Whittle, Alex Bayliss, Frances Healy, Nicki Whitehouse, Rick Schulting and others, we know that the appearance of Neolithic material culture and practices in Britain and Ireland had a very specific trajectory, tempo 
and timing.

How much do these new data and interpretations challenge our preexisting models? In Clarke's terms are we actually testing our iconic analogues with these new data? In Ireland and Britain much has been made of the apparent distinction between Mesolithic and Neolithic evidence. In discussion of the changes, Julian Thomas writes that the "...cultural change that took place around 4000 cal BC was apparently both swift and thorough, there being no mixed assemblages combining pottery with microliths..." (Thomas 2007, 426; my emphasis). The obvious corollary would follow Clarke in asking: do our models of periodized, successive cultures allow us to explore what contact between people using "Mesolithic" and "Neolithic" things might mean in terms of evidence documented from the archaeological record?

In Wylie's (1989) terms, I argue that at least in British Neolithic studies, our observations have become highly theory-laden, with the informative impacts of our concepts of "Neolithic" on our observations under-recognized. Could we identify the smoking archaeological guns? Or do we expect forms of evidence to satisfy preconceived notions of what societies were like and how change would appear in "the archaeological record" (cf. Patrik 1985)? It seems unlikely that we will find archaeological assemblages which match preconceived perioddefined criteria, and this approach runs the risk of missing potential subtleties in assemblages which are available to us for study (cf. Brophy 2004).

Rather than defining the "Neolithic" — or other "cultural" entities as proper nouns - as things that we can find in the archaeological record, we should see better regard these as adjectives, as attributes which describe differences (e.g. mesolithic). Our analytical categories will never be sufficient to produce accurate impressions of the past, but by destabilizing the nature of these cultural concepts as things we can actually "find", we might better remind ourselves of the narrative impacts which our epistemology can have.

A couple of case studies serve to highlight the tensions between the approaches to prehistoric analytical catagories, models of change and 
evidence provided by recent developments in chronological precision. At sites such as Holbeck Park, Cumbria, UK, "Neolithic" pottery, polished stone axe flakes, and domesticated cereals were recovered from a treethrow along with a "Mesolithic" rod microlith stone tool (cf. Griffiths 2011). Four statistically consistent earlier fourth millennium radiocarbon results (Ward and Wilson 1978; $\mathrm{T}^{\prime}=1.0 ; \mathrm{T}^{\prime} 5 \%=7.8 ; \mathrm{df}=3$; 3960-3780 cal BC SUERC-10772; 3950-3710 cal BC SUERC-10773; 3960-3770 cal BC SUERC-10777; 3960-3780 cal BC SUERC-10778; $95 \%$ confidence) were produced on single-entity, short-lived, charred plant remains including a cereal grain from the feature. These measurements could be consistent with late "Mesolithic" or early "Neolithic" presence in the region. Several interpretations of the processes by which the assemblage was formed can be made; the taphonomy of the material in the treethrow could be complex. Even if the use of the pottery, the other early Neolithic material culture, and the rod microlith are not demonstrably contemporaneous, this deposit suggests the potential for closely related practices at this time and in this part of the world. The presence of terminal Mesolithic and early Neolithic material culture within a treethrow is consistent with a pattern of continuity of practice between groups using these material culture types in other parts of the country (cf. Evans et al. 1999; Barclay 2000; Lamdin-Whymark 2008).

Arguably this is the "moment" of transition. This is the smoking gun. Not the one that we might expect, but a co-presence in the landscape which is part of the processes of social change which archaeologists are meant to be investigating. If our "neutral" Culture History-derived models structure our thinking in such a directional, linear and teleological manner that everywhere in Britain all "Mesolithic" practices proceed all "Neolithic" ones, then they are not very neutral. Whichever process(es) resulted in the formation of the fills of the Holbeck Park feature our pre-existing models of sequential "Mesolithic" and "Neolithic" cultures seem unlikely to unpick them. In this case, "cultures" have become defined as materially-fixed metaphysical entities.

In Yorkshire and Humberside, UK, recent analysis of the available chronological evidence for late Mesolithic and early Neolithic activity 
has demonstrated that people used "Mesolithic" hunter-gatherer-fisher material culture at the same times as "Neolithic" people farmed and built monuments (Griffiths 2014a; 2014b). There may be some spatial variation between these practices, with people using Mesolithic microlith technology present in the Pennine uplands to the west of the region, and people using domesticated plant and animal resources, pottery, polished stone axes, and building monuments to east of the region. Or there may be preservation or excavation bias. The presence of late Mesolithic material at uplands sites such as March Hill and South Haw (Griffiths 2014a) represent the foci for repeated activity over hundreds of years (based on analysis of radiocarbon dates and lithic typologies). Whatever narrative we provide, in the $39^{\text {th }}$ and $38^{\text {th }}$ centuries cal BC in this part of England people were engaging with these different practices at the same time.; there is not necessarily a universal, totalizing, culturally directional sequence. A model which fixed "cultures" as chronologically- defined metaphysical entities will not enable us to engage with the social processes resulting in this patterning in time and spsace.

These examples suggest that a model of sequential, linear "cultural" development may not be the most sophisticated rendering of the available archaeological evidence; the emerging picture is more complex. British Mesolithic/Neolithic studies have previously not had sufficiently precise or robust chronologies to require the reconciliation of evidence for overlap between different lifeways. So while considerable ink has been spilt over the British Mesolithic-Neolithic transition (e.g. Thomas 2013; Sheridan 2010 and references therein), and some of these treatments have suggested roles for "Mesolithic people" in the adoptions of farming and "Neolithic" practices, most of these latently conceive of the start of the Neolithic as the same as the end of the Mesolithic. I argue this is in part a result of iconic analogues becoming the "controlling" models which structure the kinds of questions archaeologists can envisage asking of the data.

\section{DISCUSSION}

The history of archaeological thought is often taught and written as a series of intellectual schools, which successively replaced each other, 
moving from Culture History, to Processual or New archaeology, to Post-processual archaeology and so on, much like the tradition of Culture History successions. This narrative is necessarily simplistic, doing much to write out the personalities, subtleties, tensions, and cognitive dissonance that can exist in intellectual approaches at any point in time. As well as the perceived trends in archaeological theory, I think it is instructive in this example to think about the swings in intellectual approaches, or what Sherratt (1996) presented as a dialectic intellectual history (fig. 3). By returning to both the responses of Clarke and Renfrew to their radiocarbon revolutions we can highlight both the importance of the scientific and ordered aspects of Renfrew's Enlightened archaeology response, and Clarke's emphasis on the Romantic, relative, interpretive context in which radiocarbon data should be studied.

The real impact of the latest radiocarbon revolution should not only be the exciting, fine-grained, new chronologies, but the recognition that the use of period-defined nomenclature significantly frames and situates our interpretations. Recent developments in chronological precision throw into stark relief the pervasive nature of the existing "controlling" model of sequential change between "cultures"; we now have a prehistory we can write with robust, sub-century precision. In Britain, this demonstrates the use of "Mesolithic" and "Neolithic" material culture at the same time. In this world, models that employ chronologically successive Culture History concepts singularly limit our ability to write contextual, interpretative and reflective prehistoric narratives; we need to recognize the revolutionary implications not only of the increased precision from the Bayesian revolution, but also the importance of the context in which we write our narratives.

Employing period-specific taxonomic models of culture within a linear, sequential narrative of social change has a tendency to collapse time in a quest for simple narrative structure. Terms such as "Mesolithic" are not neutral when employed in a chronologically successive model; they are parts of an iconic analogue for how we understand change over time. By glossing variability in the archaeological record we risk abstracting time, reifying change into binary flips between binary lifeways, and imposing predetermined archaeological concepts onto 
myriad material evidence. If we can emphasize archaeological analytical terms as constructs -inventions of the late $20^{\text {th }}$ century to paraphrase Mark Pluciennik (2014) — and use them as heuristic devises or iconic analogues that we test explicitly, we stand a chance of not mistaking models for data. As Wylie $(1989,10)$ notes our idea of Neolithic culture and its temporal and spatial constitution needs to allow the potential for revision. Archaeological theories of time that represents it as linear, directional, and above all teleological are ones in which abstraction provides a means to move beyond the analytical scales of the specific (for example the site) and towards the generalizing, totalizing narrative (cf. Thomas 1996). But this comes at a cost. While we might regard our periodization models as empty of narrative content and devoid of any specific meaning this is not the case if our "periods" are cultural, and linear, and successive (cf. Lucas 2005, 50).

In the light of this radiocarbon revolution we would do well to return to Clarke's discussion of the implications of scientific dating revolutions. As Clarke noted, there exists "... a class of problems ... which cannot be explained in [a] system's current form and we therefore move to new languages and new disciplinary systems not only to answer former questions which could not be answered but also to abandon former questions and answers which had no meaning" (Clarke 1973, 17; my emphasis).

\section{CONCLUSION}

By discussing the context of earlier radiocarbon revolutions I hope to have demonstrated that there are wider ranging implication of the Bayesian revolution beyond the construction of newly precise chronologies, and that these have direct bearing on the kinds of archaeological narratives we write and the kinds of causal models we are able to marshal. For this latest Bayesian radiocarbon revolution to have its full impact on archaeological practice, the rigor of the New chronological comparative order needs to be married with a Romantic reflection on the relative, interpretative contexts in which these data are analyzed. We need models of prehistory that are accurate and precise, with interpretive understandings of material culture and the nature of 
our construction of knowledge. We need, in short, to be a little more New Romantic in our approaches.

\section{ACKNOWLEDGMENTS}

This paper developed out of my post-doctoral research, following my $\mathrm{PhD}$ which was supervised by Professors Alex Bayliss and Alasdair Whittle. Two archaeologists who sadly passed away in 2016, Alan Saville and Mark Pluccenick, were extremely generous to me during this period and this paper is dedicated to their insight and kindness. Two anonymous reviewers are thanked for their comments.

\section{REFERENCES}

Barclay, A. 2000. Spatial histories of the Neolithic: a study of the monuments and material culture of southern Central England. Unpublished $\mathrm{PhD}$ thesis: University of Reading.

Bayliss, A. 2009. Rolling out the revolution: using radiocarbon dating in archaeology. Radiocarbon 51, 1, 123-47.

Binford, L. 1972. Contemporary model building: paradigms and the current state of Palaeolithic research. In D. Clarke (ed). Models in Archaeology. London: Methuen, 109-66.

Bronk Ramsey, C. 2008. Radiocarbon dating: revolutions in understanding. Archaeometry 50, 2, 249-75.

Brophy, K. 2004. The searchers: the quest for causewayed enclosures in the Irish sea area. In V. Cummings and C. Fowler (eds), The Neolithic of the Irish sea. Materiality and traditions of practice, 37-45. Oxford: Oxbow.

Childe, V. 1940. Prehistoric communities of the British Isles. London: Chambers.

Childe, V. 1929. The Danube in Prehistory. Oxford: Oxford University Press.

Clarke, D. 1972. Models in Archaeology. London: Methuen. 
Clarke, D. 1973. Archaeology: the loss of innocence. Antiquity, 47, 6-18.

Daniel, G. 1941. The megalithic colonisation of prehistoric Europe. Antiquity, 7, 1-49.

Daniel, G. 1970. Megalithic answers. Antiquity, 44. 260-9.

Daniel, G. 1981. A Short History of Archaeology. London: Thames and Hudson Ltd.

Daniel, G. 1986. Some Small Harvest: The Memoirs of Glyn Daniel. London: Thames and Hudson.

Evans, C., Pollard, J. and Knight, K. 1999. Life in woods: tree-throws, 'settlement' and forest cognition. Oxford Journal of Archaeology, 18, 3, $241-54$.

Gräslund, B. 1987. The Birth of Prehistoric Chronology. Cambridge: Cambridge University Press.

Griffiths, S. 2011. Chronological modeling of the mesolithic-neolithic transition in the midlands and north of England. Unpublished PhD thesis: Cardiff University.

Griffiths, S. 2014a. Points in time. The mesolithic-neolithic transition and the chronology of late rod microliths in Britain. Oxford Journal of Archaeology 33, 3, 221-43.

Griffiths, S. 2014b. A Bayesian radiocarbon chronology of the early Neolithic of Yorkshire and Humberside. The Archaeology Journal, 171, 2-29.

Griffiths, S. 2016. Chapter 10. Beside the ocean of time: a chronology of Neolithic burial monuments and houses in Orkney. In C. Richards and R. Jones (eds), The Development of Neolithic House Societies in Orkney. Oxford: Windgatherer Press.

Johnson, M. 1999. Archaeological Theory. An Introduction. Oxford: Blackwell. 
Lamdin-Whymark, H. 2008. The Residue of Ritual Action: Neolithic Deposition Practices in the Middle Thames Valley. Oxford: Archaeopress.

Lucas, G. 2005. The Archaeology of Time, London: Routledge.

Lucas, G. 2016. The paradigm concept in archaeology. World Archaeology, DOI: 10.1080/00438243.2016.1252688.

Lubbock, J. 1865. Prehistoric Times as Illustrated by Ancient Remains and the Manners and Customs of Modern Savages. London: Williams and Norgate.

Montelius, O. 1899. Der Orient und Europa. Stockholm, Konigl. Akademie der schonen Wissenschaften, Geschichte and Alterhumskunde.

Orton, C. 2004. Mathematical modeling. Internet Archaeology, 15, http://dx.doi.org/10.11141/ia.15.6

Patrik, L. 1985. Is there an archaeological aecord? Advances in Archaeological Method and Theory, 8, 27-62.

Piggott, S. 1954. Neolithic Cultures of the British Isles. Cambridge: Cambridge University Press.

Piggott, S. 1959. The radio-carbon date from Durrington Walls. Antiquity 33, 132, 289-90.

Pluciennik, M. 2014. Historical frames of reference for 'huntergatherers'. In V. Cummings, P. Jordan and M. Zvelebil (eds). The Oxford Handbook of The Archaeology and Anthropology of HunterGatherers. Oxford: Oxford University Press, 55-68.

Renfrew, C. 1976. Before Civilization: the Radiocarbon Revolution and Prehistoric Europe. Harmondsworth: Penguin.

Renfrew, C. 1979. Investigations in Orkney. London: Society of Antiquaries.

Sheridan, J. 2010. The Neolithisation of Britain and Ireland: the Big 
Picture. In B. Finlayson and G. Warren (eds). Landscapes in Transition. Oxford: Oxbow, 89-105.

Sherratt, A. 1979. Problems in European Prehistory. In N. Hammond, G. Isaac, R. Chapman, A. Sherratt and S. Shennan (eds). Analytical Archaeologist: Collected Papers of David L. Clarke. London: Academic Press, 192-206.

Sherratt, A. 1996.'Settlement patterns' or 'landscape studies'? Archaeological Dialogues, 3, 2, 140-59.

Thomas, J. 1996. Time, Culture and Identity. London: Routledge.

Thomas, J. 2007. Mesolithic-Neolithic transitions in Britain: from essence to inhabitation. In A. Whittle and V. Cummings (eds). Going over: the Mesolithic- Neolithic transition in north-west Europe. Oxford: Oxford University Press, 423-39.

Thomas, J. 2013. The Birth of Neolithic Britain: An Interpretive Account. Oxford: Oxford University Press.

Trigger, B. 2006. A History of Archaeological Thought. Second Edition. Cambridge: Cambridge University Press.

Ward, G., and Wilson, S., 1978. Procedures for comparing and combining radiocarbon age determinations: a critique. Archaeometry 20, 19-31.

Whitehouse, N., Schulting, R., McClatchie, M., Barratt, P., McLaughlin, T., Bogaard, A., Colledge, S., Marchant, R., Gaffrey, J. and Bunting, M. 2014. Neolithic agriculture on the European western frontier: the boom and busrt of early farming in Ireland. Journal of Archaeological Science, 51, 181-205.

Whittle, A., Healy, F. and Bayliss, A. 2011. Gathering time. Dating the early Neolithic enclosures of southern Britain and Ireland. Oxford: Oxbow.

Wylie, A. 1989. Archaeological cables and tacking: the implications of practice for Bernstein's 'Options beyond objectivism and relativism'. 
Philosophy of the Social Sciences, 19, 1-18.

\section{FIGURES}

Fig. 1. One of Childe's (1929) models of the organisation of cultures in time and space. The ways the iconic models can structure archaeological interpretations was noted by Clarke.

Fig. 2. Clarke's (1972) taxonomy of archaeological models, including the identification of representations of the distribution of archaeological evidence in of time and space (plans, maps, graphs and so on) as iconic analogues, designed as frames to test relationships.

Fig. 3. Sherratt's (1996) model of the development of intellectual thought. Romantic, contextual aspects can be seen in Clarke's responses to the first two radiocarbon revolutions, and ordered, comparative aspects can be seen in Renfrew's responses to the same changes. 